\title{
A systematic review of experiences of advanced practice nursing in general practice
}

\author{
Michael Jakimowicz ${ }^{*}$ (D), Danielle Williams ${ }^{2}$ and Grazyna Stankiewicz ${ }^{3}$
}

\begin{abstract}
Background: Despite efforts to achieve conceptual clarity, advanced practice nursing continues to reside in a liminal space, unable to secure ongoing recognition as a viable means of healthcare delivery. This is particularly evident in general practice where advanced practice role development is more fluid and generally less supported by the hierarchical structures evident in the hospital system. This review synthesises published qualitative studies reporting experiences of advanced practice nursing in general practice. The panoramic view provided by patients, nurses and doctors within this novel context, offers a fresh perspective on why advanced practice nurses have struggled to gain acceptance within the healthcare milieu.

Methods: We conducted a systematic review of qualitative studies that explored the experiences of patients, nurses and doctors who had contact with advanced practice nurses working in general practice. Published work from 1990 to June 2016 was located using CINAHL and PubMed. The full text of relevant studies was retrieved after reading the title and abstract. Critical appraisal was undertaken and the findings of included studies were analysed using the constant comparative method. Emergent codes were collapsed into sub-themes and themes.

Results: Twenty articles reporting the experiences of 486 participants were included. We identified one major theme: legitimacy; and three sub-themes: (1) establishing and maintaining confidence in the advanced practice nurse, (2) strengthening and weakening boundaries between general practitioners and advanced practice nurses and (3) establishing and maintaining the value of advanced practice nursing.

Conclusions: We set out to describe experiences of advanced practice nursing in general practice. We discovered that general practitioners and patients continue to have concerns around responsibility, trust and accountability. Additionally, advanced practice nurses struggle to negotiate and clarify scopes of practice while general practitioners have trouble justifying the costs associated with advanced practice nursing roles. Therefore, much work remains to establish and maintain the legitimacy of advanced practice nursing in general practice.
\end{abstract}

Keywords: Advanced practice, General practice, Systematic review, Qualitative research

\section{Background}

There is an absence of clear agreement regarding the concept of advanced practice nursing both in Australia and overseas [1-5]. Efforts to clarify this uncertainty have concentrated on nomenclature [1], scope [6, 7] and domains of practice $[2-5]$. We argue that this uncertainty has constrained the transition to unqualified acceptance, wedging

\footnotetext{
* Correspondence: Michael.Jakimowicz@utas.edu.au

${ }^{1}$ School of Health Sciences, University of Tasmania, 1 Leichhardt Street,

Darlinghurst, NSW 2010, Australia

Full list of author information is available at the end of the article
}

advanced practice nursing into a liminal space with little scope for recognition and expansion. This is particularly evident in general practice, where advanced practice role development is more fluid and generally less supported by the hierarchical structures evident in the hospital system [5].

Within the general practice arena, nurses perform advanced practice duties including diabetes education, chronic disease management and mental health casework, supplanting work performed previously by a general practitioner [8-10]. It is generally agreed that this range of responsibilities meets the international expectations of advanced 
practice nursing in terms of comprehensive care, systems support, education, research and professional leadership $[3,4]$.

Most research in the general practice area has focused on either (1) Nurse Practitioners, a subset of advance practice nurses with legislative status or (2) Practice Nurses, a larger set of nurses who work in general practice that includes advance practice nurses. A review by McInnes et al. [11] and a study by Merrick et al. [12] provided worthwhile understandings of challenges to teamwork, collaboration and decision-making in the general practice environment without specifically tackling issues surrounding advanced practice nursing. Other studies focused on nurses performing certain roles $[13,14]$, working in specific contexts $[10,15]$, or managing particular illnesses [16-18].

The purpose of this review is to synthesise published qualitative studies reporting experiences of advanced practice nursing in general practice. The panoramic view provided by patients, nurses and doctors within this novel context, offers a fresh perspective on why advanced practice nurses have struggled to gain acceptance within the healthcare milieu. This new data will inform wider debates concerning the establishment and continuity of advanced practice roles, independent of setting.

\section{Methods}

\section{Research question}

Our research question was framed using the Population Exposure Outcome (PEO) method as described by Bettany-Saltikov [19]. This framework simplified the search process and facilitated a more focused assessment of the retrieved studies.

We were only interested in the experiences $(\mathrm{O})$ of patients, nurses and doctors $(\mathrm{P})$ who had contact with advanced practice nurses working in general practice (E). We were cognisant of international variations in the use of the term 'advanced practice', so we agreed to use Roche et al.'s [5] broader and, therefore, more inclusive definition which was the display of a skill set beyond generic nursing work. While in no way discounting the importance of basic nursing tasks, it was important to establish that advanced practice nursing involved additional responsibilities incorporating sophisticated critical reasoning than would not normally be expected of a nurse working at a more junior level. While it could be argued that the intangibility of these higher order skills could lead to errors in recognition, in practice it is relatively straightforward to distinguish what is and what is not advanced practice nursing [1]. In the case of advanced practice nurses working in general practice, this additional work includes, but is not limited to, case management, peer education, chronic disease management, counselling and health promotion. Table 1 provides two examples common to the general practice setting to highlight this delineation.

Experiences of the work of a Nurse Practitioner (NP) were also included in the study. Patient participants had to have experience of advanced practice nursing as a current or former patient of a general practice. Nurse participants could be either advanced practice nurses or those being supervised or otherwise interacting with advanced practice nurses. Doctors could be located within the practice in the case of general practitioners (GPs) or extrinsic in the case of specialists.

\section{Search methods}

We located published work from 1990 to June 2016 using the CINAHL and PubMed databases. Preliminary searches revealed that the terms "advanced practice" and "advanced practice nursing" did not capture relevant literature, so we decided to use the broader term of "nursing". Medical Subject Headings (MeSH) terms for general practice were combined with $\mathrm{MeSH}$ terms and text words for nursing and $\mathrm{MeSH}$ terms for qualitative research. We limited the search to journal articles in English with the full text available. The search strategies for each database are provided in an additional file [see Additional file 1]. In total, we located 143 studies from PubMed and 45 from CINAHL. Two studies from the authors' personal collections were also added to this initial group. After discarding duplicate studies, we read the title and abstract of the located articles. Studies reporting survey results needed to include themes derived from "free text" responses. We retrieved the full text of studies that appeared to include relevant data or

Table 1 Comparison of generic and advanced practice nursing

\begin{tabular}{|c|c|c|}
\hline Nursing task & Generic nursing action & Advanced practice nursing action \\
\hline $\begin{array}{l}\text { Measure blood } \\
\text { pressure. }\end{array}$ & $\begin{array}{l}\text { Record result, recognise hypertension, advise } \\
\text { general practitioner of result. }\end{array}$ & $\begin{array}{l}\text { Record result, recognise hypertension, obtain patient and family history, discuss } \\
\text { treatment options, organise a referral to a general practitioner, discuss the case } \\
\text { with the general practitioner in detail, accept responsibility for case management } \\
\text { including patient education and further monitoring. }\end{array}$ \\
\hline $\begin{array}{l}\text { Assess mental } \\
\text { status. }\end{array}$ & $\begin{array}{l}\text { Record result, recognise increased agitation, } \\
\text { advise general practitioner of situation. }\end{array}$ & $\begin{array}{l}\text { Record result, recognise increased agitation, initiate emergency response if required, } \\
\text { use de-escalation techniques developed through formal skills training, organise a } \\
\text { referral to a general practitioner, discuss the case with the general practitioner in } \\
\text { detail, accept responsibility for ongoing case management including counselling and } \\
\text { further monitoring. }\end{array}$ \\
\hline
\end{tabular}


information. Forty-five studies were retrieved and examined for eligibility.

\section{Study selection}

We developed a critical appraisal tool for this study that focused on methods, analysis and interpretation. The tool was based on the Critical Appraisal Skills Programme (CASP) Checklist for Qualitative Studies [20]. We included an additional screening question that referred to our agreed definition of advanced practice nursing (provided above). Preliminary searches revealed that this step was not feasible during the initial search process. The modified critical appraisal tool is provided in an additional file [see Additional file 2]. Studies were included in the review if questions one, two and three and most of the remaining questions were answered "yes". Study selection was completed by the lead author and reviewed by the co-authors. The critical appraisal score sheets for each of the included studies is provided in an additional file [see Additional file 3]. The critical appraisal score sheets for the excluded studies is also provided in an additional file [see Additional file 4]. A flow chart describing the results of the search and selection process is provided in Fig. 1.

\section{Synthesis of findings}

The full text of included studies was exported to the NVivo $11^{\mathrm{TM}}$ software program. A list of preliminary codes was developed after close reading of the findings/ results section of a selected article. These codes were further refined during analysis of the remaining articles, using the constant comparative method [21]. Text was coded line-by-line and a code tree was used to identify emergent themes. Sub-themes were derived from direct participant quotes and synthesised interpretations. These sub-themes were further analysed and collapsed into one major theme.

\section{Findings}

Twenty articles reporting the experiences of 486 participants were included in the review. Studies were conducted in Australia (10), New Zealand (1), Canada (3), the United Kingdom (5) and continental Europe (1). A summary of these studies is provided in Table 2. The number of participants has been included to highlight the relative weight of patient, nurse and doctor experiences. Overall, we found that there was a paucity of quality studies specifically exploring this phenomenon. Several studies from the United States, a country with a large cohort of advanced practice nurses, were retrieved but subsequently excluded after critical appraisal. Twenty-five studies were excluded in total.
A total of 27 descriptors were used to code the data. We identified three sub-themes: (1) establishing and maintaining confidence in the advanced practice nurse, (2) strengthening and weakening boundaries between general practitioners and advanced practice nurses and (3) establishing and maintaining the value of advanced practice nursing. These were aggregated into one major theme: legitimacy. A diagram showing the relationship of the codes to the sub-themes and major theme is shown in Fig. 2. A list of the studies that contributed to each code and sub-theme is provided in an additional file [see Additional file 5].

\section{Sub-theme 1 - Establishing and maintaining confidence in the advanced practice nurse}

Nineteen out of twenty included studies contributed to this sub-theme $[8-10,15,22-36]$. Of the eight codes used in the aggregation of this sub-theme, the following six codes contributed the greatest amount and are presented below: development, relinquishing, responsibility, trust, accountability and referrals.

\section{Establishing confidence in the advanced practice nurse through development}

We found that confidence in advanced practice nurses in general practice was established through development activities. Professional development included formal education [22], self-directed learning [23], structured learning pathways [10] and research activities [22]. One study reported that funding of professional activities was an issue [24]. Some nurses were content with their current duties and chose not to participate in further education with a participant stating '(we have to) accept that there's a lot of nurses that don't want any more responsibility, or they don't want to extend their roles. They are happy to work within... what they currently do' [25, p. 3]. Others used the knowledge provided to help them to develop their role further [24, 26]. In some cases, this involved conducting their own development activities within the general practice as part of staff training and mentoring [27-29] and in the community as part of public health programs [25].

We also found a tension between the need to undertake professional development and the drive to establish independent practice. Some nurse practitioners were adamant that professional status would not result from more education, but from a wider scope of practice [30]. Other advanced practice nurses went so far as to claim that skilling less qualified nurses devalued their own training that, in many cases, had cost them thousands of dollars [9]. It was also noted that a minority of GPs still doubted that 


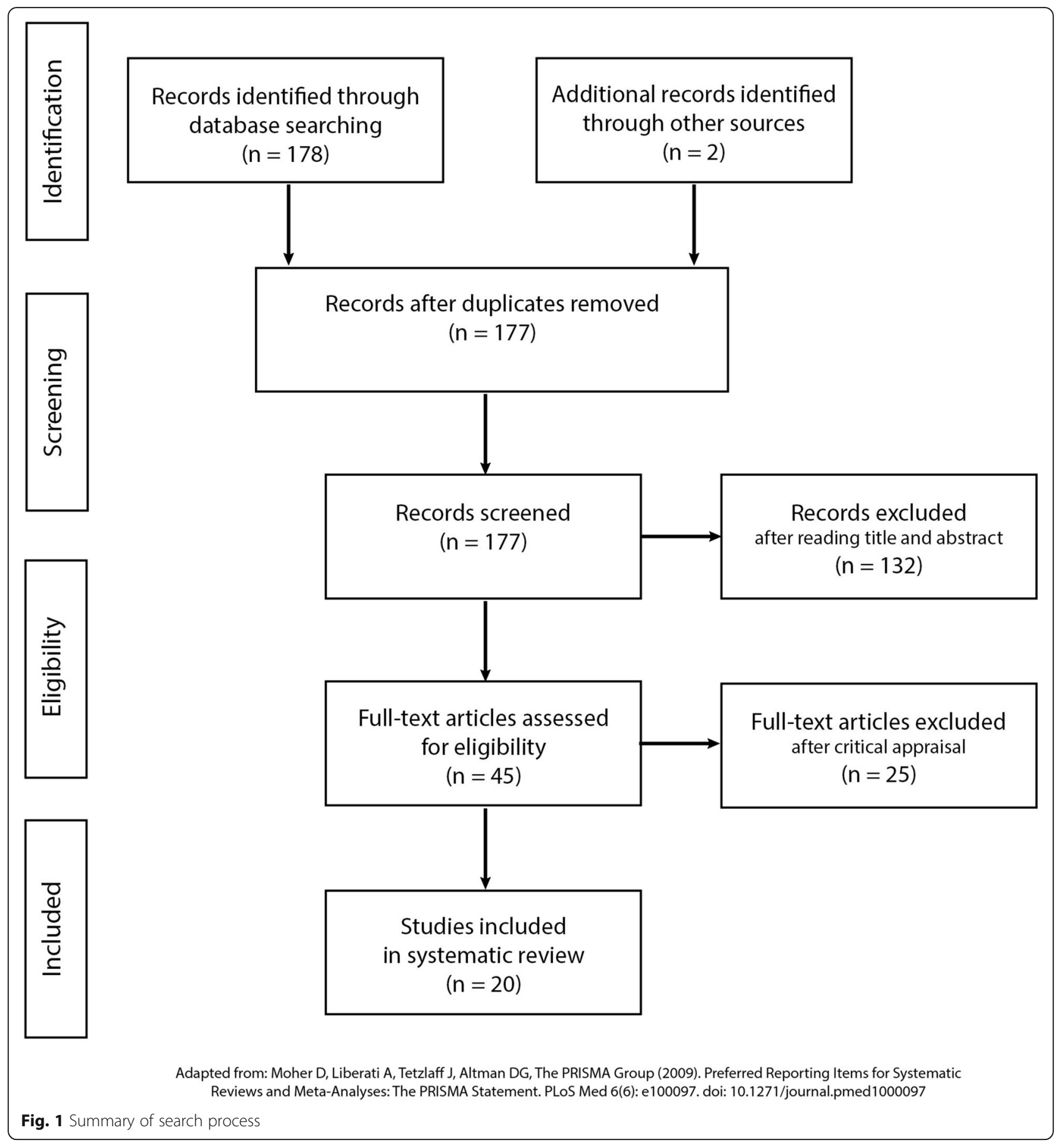

advanced practice nurses had sufficient education to complete their role [25].

\section{General practitioners relinquishing control to display confidence in the advanced practice nurse}

We found that over time, GPs became satisfied that they could relinquish certain duties and hand over full or partial responsibility for a range of care activities to advanced practice nurses $[28,31]$. This included allowing the advanced practice nurse freedom to operate within their scope of practice [24]. Indeed, GPs considered themselves quite peripheral to the advanced practice nurses in the context of diabetes care, who, they argued had more time to educate patients about glycaemic control [9]. This was also the case with cervical screening, a task that many GPs felt uncomfortable about performing [25]. However, 
Table 2 Studies included in the review

\begin{tabular}{|c|c|c|c|c|}
\hline Author(s) & Study location & Methodology and method(s) & Sampling and participants & Phenomena \\
\hline Blackburn et al. [22] & United Kingdom & $\begin{array}{l}\text { Qualitative } \\
\text { Semi-structured interviews }\end{array}$ & $\begin{array}{l}\text { Purposive } \\
17 \text { general practitioners (GPs) } 17 \text { nurses }\end{array}$ & Raising the topic of weight \\
\hline Ehrlich et al. [34] & Australia & $\begin{array}{l}\text { Grounded Theory } \\
\text { Semi-structured interviews }\end{array}$ & $\begin{array}{l}\text { Purposive } \\
10 \text { GPs } 6 \text { nurses }\end{array}$ & Care coordination \\
\hline Ehrlich et al. [32] & Australia & $\begin{array}{l}\text { Qualitative interpretive } \\
\text { Semi-structured focus group } \\
\text { interviews }\end{array}$ & $\begin{array}{l}\text { Purposive } \\
9 \text { nurses }\end{array}$ & Care coordination \\
\hline Eley et al. [33] & Australia & $\begin{array}{l}\text { Mixed Methods } \\
\text { Interviews and self-reported } \\
\text { questionnaires }\end{array}$ & $\begin{array}{l}\text { Randomised } \\
8 \text { GPs } 4 \text { nurses } 10 \text { patients }\end{array}$ & Chronic disease management \\
\hline Furler et al. [9] & Australia & $\begin{array}{l}\text { Qualitative } \\
\text { Semi-structured interviews }\end{array}$ & $\begin{array}{l}\text { Purposive } \\
7 \text { GPs } 5 \text { nurses } 18 \text { patients }\end{array}$ & $\begin{array}{l}\text { Nurse-led model of care for insulin } \\
\text { initiation for patients with Type } 2 \\
\text { Diabetes Mellitus (T2DM) }\end{array}$ \\
\hline Furler et al. [36] & Australia & $\begin{array}{l}\text { Qualitative } \\
\text { Semi-structured interviews }\end{array}$ & $\begin{array}{l}\text { Purposive } \\
10 \text { GPs } 4 \text { diabetes nurse specialists } \\
\text { (DNSs) } 12 \text { patients }\end{array}$ & $\begin{array}{l}\text { Barriers and enablers to timely } \\
\text { initiation of insulin }\end{array}$ \\
\hline $\begin{array}{l}\text { Johnson and Goyder } \\
\text { [26] }\end{array}$ & United Kingdom & $\begin{array}{l}\text { Qualitative } \\
\text { Semi-structured interviews }\end{array}$ & $\begin{array}{l}\text { Purposive } \\
12 \text { GPs } 3 \text { DNSs } 2 \text { nurses }\end{array}$ & Integrated diabetes care \\
\hline Mahomed et al. [8] & Australia & $\begin{array}{l}\text { Grounded theory } \\
\text { In-depth interviews }\end{array}$ & $\begin{array}{l}\text { Purposive } \\
38 \text { patients }\end{array}$ & $\begin{array}{l}\text { The process of patient satisfaction } \\
\text { with nurse-led chronic disease } \\
\text { management in general practice }\end{array}$ \\
\hline Main et al. [30] & United Kingdom & $\begin{array}{l}\text { Grounded theory } \\
\text { Semi-structured }\end{array}$ & $\begin{array}{l}\text { Purposive } \\
10 \text { GPs } 8 \text { nurse practitioners (NPs) } \\
1 \text { practice nurse } 2 \text { managers }\end{array}$ & $\begin{array}{l}\text { Barriers to integration of NPs in } \\
\text { primary care }\end{array}$ \\
\hline $\begin{array}{l}\text { Manski-Nankervis et al. } \\
\text { [35] }\end{array}$ & Australia & $\begin{array}{l}\text { Qualitative } \\
\text { Semi-structured interviews }\end{array}$ & $\begin{array}{l}\text { Purposive } \\
21 \text { GPs, practice nurses and DNSs }\end{array}$ & $\begin{array}{l}\text { The roles and relationships } \\
\text { between health professionals } \\
\text { involved in insulin initiation }\end{array}$ \\
\hline McKenna et al. [24] & Australia & $\begin{array}{l}\text { Qualitative } \\
\text { Semi-structured interviews }\end{array}$ & $\begin{array}{l}\text { Purposive } \\
23 \text { stakeholders }\end{array}$ & $\begin{array}{l}\text { Barriers and enablers influencing } \\
\text { the development of advanced } \\
\text { nursing roles in general practice }\end{array}$ \\
\hline McKinlay et al. [10] & New Zealand & $\begin{array}{l}\text { Qualitative } \\
\text { Semi-structured interviews }\end{array}$ & $\begin{array}{l}\text { Unclear } \\
17 \text { nurses }\end{array}$ & $\begin{array}{l}\text { The role of general practice nurses } \\
\text { in mental health care }\end{array}$ \\
\hline Mills et al. [25] & Australia & $\begin{array}{l}\text { Grounded theory } \\
\text { Interviews }\end{array}$ & $\begin{array}{l}\text { Purposive } \\
18 \text { nurses }\end{array}$ & Cervical screening \\
\hline Mitchell et al. [29] & Canada & $\begin{array}{l}\text { Phenomenological } \\
\text { Semi-structured interviews }\end{array}$ & $\begin{array}{l}\text { Purposive } \\
16 \text { GPs }\end{array}$ & $\begin{array}{l}\text { NPs as inter-professional } \\
\text { educators }\end{array}$ \\
\hline Oandasan et al. [23] & Canada & $\begin{array}{l}\text { Case study } \\
\text { Interviews and focus groups }\end{array}$ & $\begin{array}{l}\text { Purposive } \\
7 \text { nurses }\end{array}$ & $\begin{array}{l}\text { Role and competencies of family } \\
\text { practice nurses }\end{array}$ \\
\hline Phillips et al. [37] & Australia & $\begin{array}{l}\text { Multi-method } \\
\text { Interviews, structured } \\
\text { observations and artefacts }\end{array}$ & $\begin{array}{l}\text { Illustrative } \\
37 \text { nurses } 22 \text { practice managers }\end{array}$ & $\begin{array}{l}\text { Structure and value of nurse and } \\
\text { GP labour }\end{array}$ \\
\hline Price and Williams [28] & United Kingdom & $\begin{array}{l}\text { Qualitative, exploratory } \\
\text { Individual interviews and } \\
\text { focus groups }\end{array}$ & $\begin{array}{l}\text { Pragmatic } \\
7 \text { NPs } 10 \text { GPs } 2 \text { nurse lecturers }\end{array}$ & NP referral practice \\
\hline Speed and Luker [15] & United Kingdom & $\begin{array}{l}\text { Ethnographical } \\
\text { Participant observation and } \\
\text { semi-structured interviews }\end{array}$ & $\begin{array}{l}\text { Unclear } \\
33 \text { nurses }\end{array}$ & $\begin{array}{l}\text { Methods used by GPs and nurses } \\
\text { to organise each other }\end{array}$ \\
\hline Sunaert et al. [31] & Belgium & $\begin{array}{l}\text { Qualitative } \\
\text { Semi-structured interviews } \\
\text { and focus groups }\end{array}$ & $\begin{array}{l}\text { Purposive } \\
29 \text { GPs } 10 \text { patients }\end{array}$ & $\begin{array}{l}\text { Support to GPs during insulin } \\
\text { therapy initiation }\end{array}$ \\
\hline Walsh et al. [27] & Canada & $\begin{array}{l}\text { Qualitative, descriptive } \\
\text { Semi-structured interviews }\end{array}$ & $\begin{array}{l}\text { Purposive } \\
4 \text { NPs } 17 \text { medical residents }\end{array}$ & $\begin{array}{l}\text { NPs as educators of medical } \\
\text { residents in family practice }\end{array}$ \\
\hline
\end{tabular}

McKinlay et al. [10] found that GPs were reluctant to share the care of mental health patients with advanced practice nurses because it was not an effective use of the nurses' time. Other GPs were happy to hand off care if they did not have to supervise or otherwise support the advanced practice nurse including answering questions $[15,30]$. One nurse 
stated 'I think they (doctors) are very happy to leave us to our own devices and I think they are sometimes a little bit unhappy...when we...ask them to look at things we are not happy about and that can cause conflict' [15, p. 891.]

\section{Establishing and maintaining confidence by transferring and accepting responsibility}

We found that while many GPs were prepared to handover individual tasks, fewer were willing to assign overall case responsibility to the advanced practice nurse. Two studies found that this only occurred when there were established routines and sustainable structures in place [32, 33]. It was accepted that advanced practice nurses were competent in maintaining the flow of patients through the general practice with one GP stating 'If she thinks someone needs to be seen, and when, and how, I value that. I follow her advice, and if she disagrees with me then she'll say so' [23, p. e379]. However, many GPs did not believe that advanced practice nurses were capable of being both autonomous and accountable [33]. This was reflected in the hesitancy of many nurses to assume full responsibility for patient care [30].

\section{Displaying trust to establish and maintain confidence in the advanced practice nurse}

We found that trust was an important element in establishing and maintaining confidence in advanced practice nurses in general practice. One study found that trust was the bridge between professional cultures which ultimately benefitted patients [34], while two studies highlighted the importance of medical mentorship in maintaining trust [28, 35]. Diabetic Nurse Educators (DNE) were uniquely placed in this respect because they demonstrated skills regarding insulin initiation and titration that were, in many cases, superior to a GP [35]. The DNE's relationship with endocrine specialists, allowed GPs to maintain a professional distance that was not replicated with other advanced practice nurses [35]. Another study found that patients needed to see that the DNE carried the authority of, and was trusted by, the GP [36].

Patients also trusted advanced practice nurses who displayed clinical acumen and attitudes by behaving in similar ways to a doctor [23]. Mahomed et al. [8] discovered that patients who had their care needs met were more likely to recognise the level of education, training and experience required to achieve the advanced practice nurse role. A patient in this study stated 'I presume they've all got the same training, they all know what they're doing and they know what they've got to do for me' [8, p. 2545]. Two studies found that visible and ongoing role development was an essential element of trust $[23,31]$, while another study found that advanced

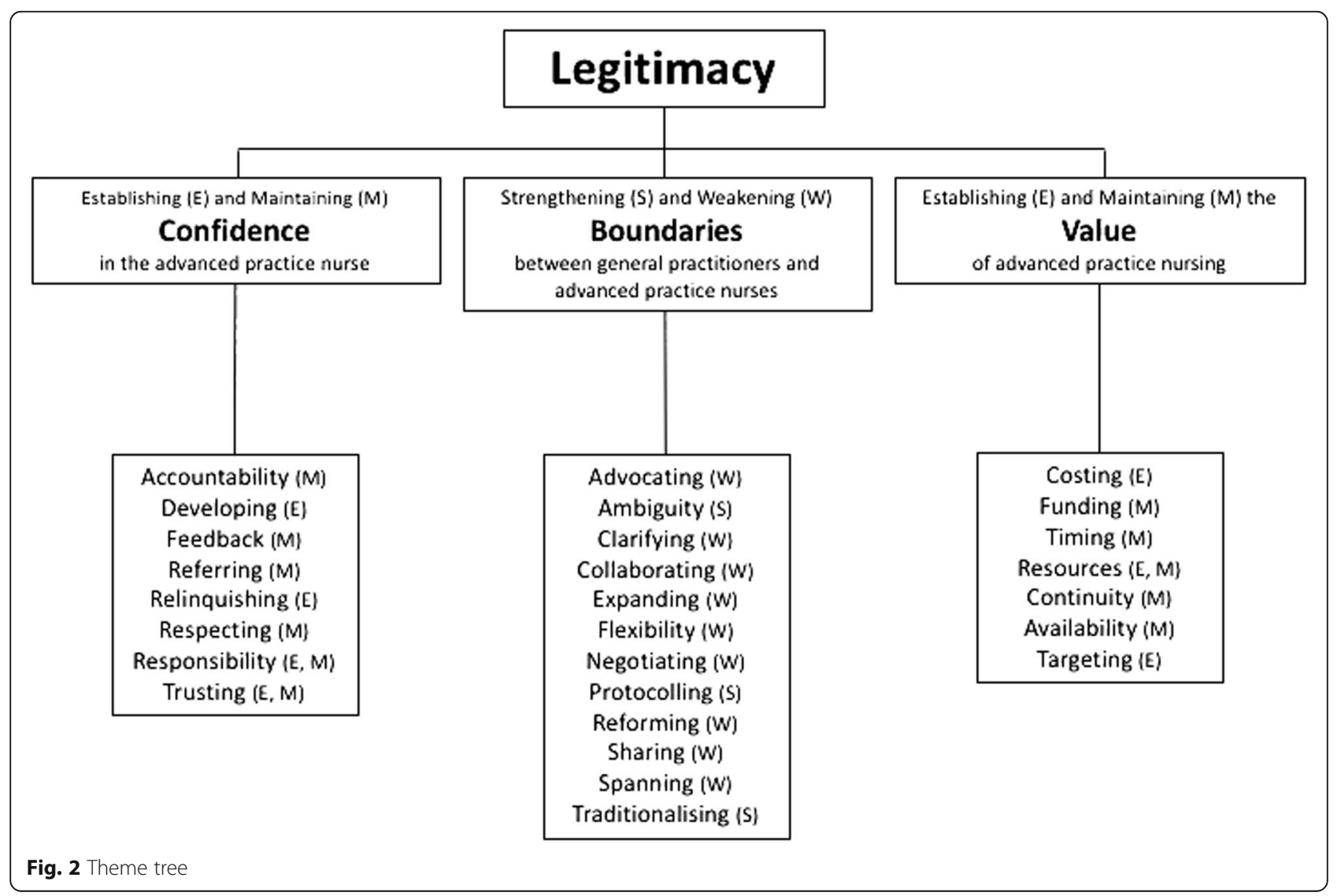


practice nurses wrestled with the expectation of being both autonomous and a team player with a broad range of professional skills [32].

\section{Advanced practice nurses maintaining confidence by accepting accountability}

We found that issues around accountability negatively affected confidence in advanced practice nurses in general practice. One study found that while the scope and responsibility of advanced practice was negotiated locally, there was universal agreement between doctors, nurses and patients that the GP was ultimately accountable for decisions made by the nurse [9]. Main et al. [30] found that many NPs were reluctant to fully utilise prescribing rights because they considered themselves to be nurses first and were uncomfortable with being viewed as elitist and acting like a doctor. A NP in this study stated 'I'm not sure where the resistance emanates from but there's possibly resistance from the Nursing and Midwifery Council...I think the argument possibly is around the fact that nursing roles are changing so fast that they don't want to make an elite group' [30, p. 483]. Senior nurses working towards NP status were in a similar situation [10].

Many patients appreciated having both a GP and an advanced practice nurse involved in their care [33]. Patients reported that the nurse was more likely to ask about any additional concerns that they may have [36]. Advanced practice nurses were also more willing to share information about themselves which put them at ease [8]. This communication style inspired patient confidence in the advanced practice nurse, however, patients did not resonate with approaches that were censorial or dictatorial [8].

\section{Doctors maintaining confidence by respecting referrals from} advanced practice nurses

We found that some GPs were reluctant to endorse referrals made by NPs to specialists outside the practice on their behalf $[28-30,36]$. Some specialists refused to recognise the referral at all and berated the responsible GP for allowing the normal protocol to be bypassed [28]. This gave advanced practice nurses the impression that they were trusted within the walls of the general practice, but not in a way that was visible to the outside world [30]. Of note, was an effort by one advanced practice nurse to reclaim stature by declaring that her role was central to the operation of the practice. She stated 'we're, you know running the ship, meaning we're not able to free up time' [27, p. e320].

Sub-theme 2 - Strengthening and weakening boundaries between general practitioners and advanced practice nurses

Every included study contributed to this sub-theme [8$10,15,22-37]$. Of the 12 codes used in the aggregation of this sub-theme, the following eight codes contributed the greatest amount and are presented below: ambiguity, traditionalising, clarifying, protocolling, reforming, flexibility, collaboration and negotiation.

\section{Strengthening the boundary between general practitioners and advanced practice nurses by maintaining the ambiguity of advanced practice nursing roles and responsibilities}

One study discovered that despite being supervised by NPs in the initial stages of their training, GP residents were still unclear about the NP's scope of practice [27]. This uncertainty was also evident in three other studies where more experienced GPs stated that the advanced practice nurse scope of practice was ill-defined and ambiguous [15, 30, 31]. Without a clear understanding of the roles and responsibilities of the advanced practice nurse, some general practitioners lost interest in the position and became disconnected from the advanced practice nurse. This vacuum acted as a boundary between the two areas of practice.

\section{Strengthening the boundary between general practitioners and advanced practice nurses by traditionalising doctor- nurse relationships}

In an attempt to narrow this gap, some GPs resorted to traditionalising their relationship with the nurse [10, 15, $25,27,28,30-32,34,35,37$ ]. Speed et al. [15] noted incidences of GPs disciplining nurses over the standard of their paperwork. One study reported a case where a GP rationalised role demarcation to who earned the income to pay the nurses [30]. Three studies found that this discordance came down to the initial limited understanding of patients' needs by the GP [10, 32, 34] which subsequently restricted the capabilities of the advanced practice nurse downstream.

We found that medicalisation of nursing roles was resisted by both nurses and doctors. Some doctors were uncomfortable with nurses making a diagnosis [28] and losing control over treatment decisions [31]. Advanced practice nurses were uneasy with performing timelimited consultations because this reduced the amount of time that they could interact with their patients with one advanced practice nurse stating 'You are booked solid and you have patient after patient, and when you go back to review they want to talk about all things and you really don't have time' [27, p. e320].

\section{Strengthening and weakening the boundary between general practitioners and advanced practice nurses through clarifying and protocolling}

Clarification both strengthened and weakened the divide between advanced practice nurses and GPs. Within environments that were micro-managed by the GP, seven 
studies reported that nurses began to doubt their care decisions and sought clarification for increasingly simple matters $[10,15,28,30,31,34,36]$. One study reported incidences where overt patient requests were overlooked because of this unnecessary interplay between nurse and doctor [34]. Twelve studies reported the development of protocols as a means of avoiding omissions and explicitly stating what duties advanced practice nurses could perform $[9,10,15,25,27,28,31-36]$. This included computer templates preloaded with pertinent patient information [32], drug initiation and titration algorithms $[9,27]$ and structured care pathways [10]. In one case a nurse stated '...it was tick the boxes, spit out the care plan, spit out the health assessment...we are not dealing with the patient as a holistic person...' [32, p. 131]. One study reported incidences where GPs believed insulin protocols were only relevant to nurses [31]. Over time, advanced practice nurses lost decision-making skills and felt their status within the practice was devalued [15]. One study found that nurses in this situation preferred to operate within broader policy frameworks [25]. Reassuringly, however, clarification was reported to improve teamwork [30] develop relationships [26] and overcome uncertainty regarding responsibility [31].

\section{Weakening the boundary between general practitioners and advanced practice nurses through reforming}

Several other behaviours narrowed the gap between GPs and advanced practice nurses. Three studies reported that more experienced GPs were prepared to reform the way care was delivered and expand the role of the advanced practice nurse $[25,28,32]$. One study reported that the ease of implementation was directly correlated with the sustainability of this reorganisation with a GP stating 'We have to make it easy... we have to make it user friendly' [32, p. 131]. Another study found that GPs were sceptical of expansion when their own workload pressures increased [31]. One study discovered an interesting tension between DNEs and PNs involving role expansion [35]. In this case, as DNEs became overloaded with additional cases, insulin initiation was delegated to PNs who did not have specialist training and this was viewed as a threat to their status within the practice [35]. Three studies found that nurses had always been trying to expand their roles, citing instances where nurses provided independently organised groups to support patients with chronic illnesses $[9,25,26]$. In another study, patients understood the limitations of care led by advanced practice nurses and realised that they would be referred to a GP if their condition became complicated [8].

\section{Weakening the boundary between general practitioners and advanced practice nurses through flexibility}

Five studies found that advanced practice nurses and GPs appreciated flexibility [15, 23, 27, 28, 37]. This included balancing multiple priorities [23] and informal communications outside of clinical treatment spaces [37]. A nurse in one study stated 'It's a real skill in family practice nursing, identifying those red flags of who needs to be seen - that triaging function' [23, p. e379]. One study found that a lack of flexibility had serious implications for ongoing relationships [15].

\section{Weakening the boundary between general practitioners and advanced practice nurses through collaboration and negotiation}

In six studies, advanced practice nurses viewed interactions with GPs as opportunities for collaboration $[9,26$, $30,32,34,35]$. A further six studies reported negotiation during these exchanges $[10,15,28,30,34,36]$. One study reported that the key components of collaborative relationships were shared knowledge, mutual respect and acceptance [35], while another highlighted the importance of mentoring and supportive networks [32]. In one study, a nurse stated '...you do work in isolation. As far as I am aware I am the only primary mental health nurse in (the area)...so I've tried to make links with a mental health nursing adviser who provides professional oversight...' [10, p. 229].

Negotiation was not confined to purely clinical interactions between GPs, advanced practice nurses and patients. One study reported that understanding and utilising key power relationships within the practice, particularly involving those with financial control, was an important skill [32]. Another study found that clinical negotiation skills included overstating a patient's condition to expedite treatment and challenging/counter-challenging [15]. Interestingly, seven studies reported that patients did not recognise interactions between the advanced practice nurse and the GP as professional cooperation $[10,15,28,30,31,34,36]$. One patient stated 'she had to get permission from Dr Ken to put me on insulin, but it was her that decided and he had to say yes' [9, p. 619].

\section{Sub-theme 3 - Establishing and maintaining the value of advanced practice nursing}

Nineteen out of twenty included studies contributed to this sub-theme [8-10, 15, 22-28, 30-37]. Of the seven codes used in the aggregation of this sub-theme, the following three codes contributed the greatest amount and are presented below: cost, funding and resources.

\section{Establishing and maintaining the value of advanced practice nursing by measuring cost, funding and resources}

Ten studies reported tensions regarding the cost of advanced practice nurses [9, 10, 24, 25, 30-34, 37]. Another five studies reported anxieties around recouping this expense $[9,24,31,32,34]$. Sixteen studies found 
that as salaried employees, advanced practice nurses measured their worth to the practice in terms of the extra services they offered and the additional time they could give to their patients [8-10, 22, 23, 25-27, 30-37]. One study found that advanced practice nurses believed that the process of establishing a connection with a patient was time consuming in the beginning but reaped dividends in terms of patient compliance [34]. However, a GP in one study stated 'the nurses can afford to spend a little bit more time with the patients than we can'[37, p. 140] implying that a GP's time was more valuable in dollar terms.

Both nurses and patients reported a reluctance to waste a doctor's time [37]. One study found that GPs were more conscious of the time versus cost considerations of advanced practice nurses than they were of other services within the general practice, including their own [30]. In another study, a GP believed that NPs were a waste of money because they always asked for a second opinion [22]. In another case, a GP proposed a funding model where patients paid an 'upfront practice payment' for services provided by an advanced practice nurse [9, p. 353]. Many GPs believed that it was not their role to provide patient education or engage in health promotion and this task was better left to the advanced practice nurse $[15,24-28,30,32,34,35,37]$. Some GPs did concede, however, that the advanced practice nurse was an effective means of providing continuity of care to vulnerable patients and many patients suffering chronic illnesses supported this view $[8,9,24$, $25,28,30-32,34]$.

\section{Major theme - Legitimacy}

The three sub-themes were related by the concept of legitimacy. While GPs, in the main, accepted the place of the advanced practice nurse in the general practice milieu, there was disagreement on how to best utilise this model of care [10, 25-28, 33, 34, 36]. On the one hand, GPs enjoyed handing over what they perceived to be mundane duties to advanced practice nurses, but resented having to pay for the audits that accompanied these tasks [32].

Eleven studies reported that advanced practice nurses stated that they were in a constant battle to be recognised professionally by their colleagues and patients $[8$, $9,23,25,26,28,30-32,34,35]$. Another study reported that this was also true in relation to other, less qualified, nursing staff [35]. While advanced practice nurses appreciated training opportunities, they struggled to maintain a caseload that was commensurate with their training [31].

Patients, particularly those who viewed their condition as serious, were reluctant to allow an advanced practice nurse to have a prominent role in their care [8]. In two studies, patients viewed the advanced practice nurse as more available than the GP in terms of appointment times, interaction style and spatial positioning within the general practice [23,33]. While mindful of the need to maintain accessibility, many advanced practice nurses wanted to be accommodated within the general practice in a similar way to the GP, viewing this as a public display of their increased stature within the general practice $[15,22,27,28,31,32,34,37]$.

\section{Discussion}

Establishing and maintaining confidence in the advanced practice nurse

The findings showed that advanced practice nurses gained confidence from participation in further training and this assurance was noticeable to colleagues and clients. However, we found that professional development played virtually no part in solidifying the role of the advanced practice nurse within general practices. NPs and DNEs who, by the nature of their position, had more education than other nurses in the practice, believed that the path to recognisable status was increasingly independent practice. They resented PNs being given extended duties after they had completed a relatively small amount of training that was mostly funded by the practice. They also believed that this devalued their on-thejob training and more comprehensive, self-funded education, giving the advanced practice nurses the impression that practice decision makers did not value the nurse's overall worth to the general practice particularly highly.

We found that there was a tendency for GPs to relinquish duties to advanced practice nurses for reasons other than the skills and abilities of the nurse. This also applied to situations where the GP retained sole responsibility for the task. In many cases, GPs handed over tasks that they had no interest in, did not enjoy performing or took up too much of their consultation time. This created an uneasy tension between GPs and advanced practice nurses because it appeared that GPs were the sole arbiter of what the nurse could or could not do.

We also reported examples where GPs were only happy to handover duties if they were not subsequently called upon by the advanced practice nurse for basic clinical advice, supervision or training. While this could be interpreted that the GP had confidence in the ability of the advanced practice nurse, pragmatically, it meant that tasks of lower clinical importance were delegated. The result of this custom was that advanced practice nurses became unsure of what they were supposed to doing and hesitant to assume additional responsibility when it was offered. Advanced practice nurses were also inclined to default to tasks such as patient flow in the absence of other meaningful work. While important to 
the day-to-day running of the practice, this task could have been delegated to more junior nurses or indeed reception staff.

Our findings showed that advanced practice nurses were not automatically bestowed with the level of trust that their skills and abilities demanded. It appeared that colleagues either side of the advanced practice nurse, were better placed in this way because they held positions and performed duties that were more easily recognised and understood by patients. To gain respect from GPs, advanced practice nurses felt that they had to display skills that were more medically oriented, however, these skills were not accepted by their less qualified nursing colleagues who themselves felt undervalued and overworked. NPs, who had statutory and nominal advantage over their advanced practice nursing counterparts, still prioritised the nursing component of their practice and were dismayed when their consultations were time restricted.

We found that the concept of accountability was used by both GPs and patients to justify an unwillingness to increase the responsibility of advanced practice nurses. Interestingly, we found that patients, nurses and doctors agreed that the GP was ultimately responsible for a patient's care in the general practice. While this view could appear to be reasonably justified, today's healthcare environment demands that every person charged with the care of patients is ultimately answerable for their own practice. Assumptions by GPs that they are responsible for everything that transpires within the practice are, therefore, dangerous because they may give colleagues the (wrong) impression that they are somehow absolved from any culpability deriving from their own care decisions. If patients also expect GPs to retain final say over their care, the advanced practice nurse is, in effect, performing a function that has little relevance. This situation has the potential to create environments where there is a reliance on standing orders and protocols, which only diminishes opportunities for independent practice by advanced practice nurses.

Referral practice was another area of our findings which further exposed the tenuous position of advanced practice nurses in general practice. This traditional view of peer-topeer referrals is supported by time honoured practices such as referral letters written in standardised, long winded formats that act to exclude newcomers to the arena who do not have a solid grasp of the nuances involved. Given that some GPs also resented advanced practice nurses making diagnoses, it is possible that the pushback from specialists was a means of preserving the last bastion of a closed fraternity.

\section{Strengthening and weakening boundaries between general practitioners and advanced practice nurses} We found that clarification was both a means of strengthening and weakening boundaries between GPs and advanced practice nurses. In practices where there was a mature relationship between the two, clarification was an empowering force that kept communication channels open and provided opportunities for wider consultation about matters central to the running of the practice. However, other associations were not so productive. In these relationships, advanced practice nurses used clarification as a means of rebuilding their own confidence. This only resulted in trivialising the duties of the advanced practice nurse to the extent that they had to be formalised in a more detailed way with protocols.

\section{Establishing and maintaining the value of advanced practice nursing}

An unexpected finding was the dialectic verbalised by GPs concerning the value of their consultation time versus the recovery of costs incurred through the provision of an advanced practice nurse. We found that on the one hand, GPs were happy to hand over some of the more time-consuming responsibilities of care to nurses to see more patients themselves and, presumably, bring more money into the practice. However, there was a limit to this pattern because nurses are, in the main, salaried from the total earnings of a general practice and recover very little in the way of rebates for their services. This balancing act placed the advanced practice nurse at a considerable disadvantage when compared to a revenue earning GP in terms of justifying their position in the long term. No other studies have identified this tension.

\section{Legitimacy of advanced practice nursing in general practice}

It is clear from our study, that advanced practice nursing does not have a legitimate foothold in general practice. We found that despite patients, nurses and doctors being able to articulate problems concerning confidence, boundaries and value, there had been scant progress towards organising this niche of practice in any sustainable way. Critical theorists such as Willis [38] would claim that this maelstrom is subtly encouraged by the medical profession as a means of asserting and supporting their dominance in the general practice sphere. However, we argue that the uncertainty surrounding advanced practice nursing in general practice is the result of a complex set of related factors that have sabotaged attempts to gain professional recognition for over a decade.

\section{Implications}

Our findings demonstrate that given recent pressures to lower healthcare costs, any attempt to reposition advanced practice nursing as a viable adjunct to medical care will be met with hesitancy by patients and GPs alike. The risk with this paralysis is that without 
imminent clarification, advanced practice nurses in general practice may be unprepared to accept increasing responsibility as the healthcare burden increases over the next few decades.

\section{Limitations}

We limited this review to qualitative literature to gain a deeper sense of the experiences of advanced practice nursing in general practice. However, many of the included studies did not report participant quotes within the results section of their papers and we, therefore, had to rely on interpretive data for our synthesis. We argue, however, that this does not diminish the ability to generalise our results because all the included studies were subjected to rigorous methodological peer review prior to publication and met our own critical appraisal standards.

\section{Conclusion}

We set out to describe experiences of advanced practice nursing in general practice. We discovered that general practitioners and patients continue to have concerns around responsibility, trust and accountability. Additionally, advanced practice nurses struggle to negotiate and clarify scopes of practice while general practitioners have trouble justifying the costs associated with advanced practice nursing roles. The qualitative literature around advanced practice nursing has shown that this form of nursing has yet to establish sustainable legitimacy in general practice. Given the similarities between this and broader healthcare contexts, we argue that our findings have implications for efforts to solidify advanced practice nursing outside of general practice.

\section{Additional files}

Additional file 1: Search strategies. Description of data: Detailed search strategies for PubMED and CINAHL. (DOCX 36 kb)

Additional file 2: Modified critical appraisal tool. Description of data: Critical appraisal form based on the CASP Checklist for Qualitative Studies. (DOCX $21 \mathrm{~kb}$ )

Additional file 3: Critical appraisal of included studies. Description of data: A consolidated document detailing the results of critical appraisal for included studies. (DOCX $70 \mathrm{~kb}$ )

Additional file 4: Critical appraisal of excluded studies. Description of data: A consolidated document detailing the results of critical appraisal for excluded studies. (DOCX $80 \mathrm{~kb}$ )

Additional file $\mathbf{5}$ List of studies contributing to each code and sub-theme. Description of data: A table listing the studies that contributed to each code and sub-theme. (DOCX $20 \mathrm{~kb}$ )

\section{Abbreviations}

CINAHL: Cumulative Index to Nursing and Allied Health Literature; DNE: Diabetic Nurse Educator; DNS: Diabetic Nurse Specialist; EndNote ${ }^{T M}$. A reference management software package; GP: General practitioner; MEDLINE: Medical Literature Analysis and Retrieval System Online; MeSH: Medical Subject Heading; NP: Nurse Practitioner; NVivo TM: A qualitative data analysis computer software package; PubMed: A free search engine accessing the MEDLINE database; T2DM: Type 2 Diabetes Mellitus

\section{Acknowledgements}

None.

\section{Funding}

The first author was supported by an Australian Government Research Training Program Scholarship.

Availability of data and materials

Relevant EndNote ${ }^{\mathrm{TM}}$ libraries and NVivo ${ }^{\mathrm{TM}}$ coding files can be obtained from the first author.

\section{Authors' contributions}

MJ conceived the study. MJ performed the data search and retrieval. All authors participated in the critical appraisal process. MJ drafted the manuscript. DW and GS revised the manuscript for content and structure. MJ performed the final edit of the manuscript. All authors have read and approved the final manuscript.

\section{Competing interests}

The authors declare that they have no competing interests.

Consent for publication

Not applicable.

Ethics approval and consent to participate

Not applicable.

\section{Author details}

${ }^{1}$ School of Health Sciences, University of Tasmania, 1 Leichhardt Street, Darlinghurst, NSW 2010, Australia. ${ }^{2}$ School of Health Sciences, University of Tasmania, Private Bag 135, Hobart, TAS 7001, Australia. ${ }^{3}$ School of Health Sciences, University of Tasmania, Locked Bag 5052, Alexandria, NSW 2015, Australia.

Received: 30 September 2016 Accepted: 27 December 2016

Published online: 18 January 2017

\section{References}

1. Dowling M, Beauchesne M, Farrelly F, Murphy K. Advanced practice nursing: a concept analysis. Int J Nurs Pract. 2013;19:131-40.

2. Por J. A critical engagement with the concept of advanced nursing practice. J Nurs Manag. 2008;16:84-90.

3. Gardner G, Chang A, Duffield C. Making nursing work: breaking through the role confusion of advanced practice nursing. J Adv Nurs. 2006:57(4):382-91.

4. Gardner G, Duffield C. Defining advanced practice nursing. Aust Nurs Midwifery J. 2013;21(6):7.

5. Roche M, Duffield C, Wise S, Baldwin R, Fry M, Solman A. Domains of practice and Advanced Practice Nursing in Australia. Nurs Health Sci. 2013:15:497-503.

6. Jokiniemi K, Haatainen K. Advanced nursing roles: a systematic review. Nurs Health Sci. 2012;14:421-31.

7. Stasa H, Cashin A, Buckley T, Donoghue J. Advancing advanced practice - Clarifying the conceptual confusion. Nurse Educ Today. 2014:34:356-61.

8. Mahomed R, St John W, Patterson E. Understanding the process of patient satisfaction with nurse-led chronic disease management in general practice. J Adv Nurs. 2012;68(11):2538-49.

9. Furler J, Blackberry I, Walker C, Manski-Nankervis J, Anderson J, O'Neal D, Young D, Best J. Stepping up: a nurse-led model of care for insulin initiation for people with type 2 diabetes. Fam Pract. 2014;31(3):349-56.

10. McKinlay E, Garrett S, McBain L, Dowell T, Collings S, Stanley J. New Zealand general practice nurses' roles in mental health care. Int Nurs Rev. 2011;58(2):225-33.

11. Mclnnes S, Peters K, Bonney A, Halcomb E. An integrative review of facilitators and barriers influencing collaboration and teamwork between general practitioners and nurses working in general practice. J Adv Nurs. 2015;71(9):1973-85.

12. Merrick E, Fry M, Duffield C, Stasa H. Trust and decision-making: How nurses in Australian general practice negotiate role limitations. Collegian (Royal College of Nursing, Australia). 2015;22(2):225-32.

13. Hamirudin A, Charlton K, Walton K, Bonney A, Potter J, Milosavljevic M, Hodgkins A, Albert G, Ghosh A, Dalley A. Feasibility of implementing routine nutritional screening for older adults in Australian general practices: a mixed-methods study. BMC Fam Pract. 2014;15:1-9. 
14. Lorch R, Hocking J, Guy R, Vaisey A, Wood A, Lewis D, Temple-Smith M. Practice nurse chlamydia testing in Australian general practice: a qualitative study of benefits, barriers and facilitators. BMC Fam Pract. 2015;16:36.

15. Speed S, Luker K. Getting a visit: how district nurses and general practitioners 'organise' each other in primary care. Sociol Health IIIn. 2006;28(7):883-902.

16. Breen A, Carr E, Mann E, Crossen-White H. Acute back pain management in primary care: a qualitative pilot study of the feasibility of a nurse-led service in general practice. J Nurs Manag. 2004;12(3):201-9.

17. Infante F, Proudfoot J, Powell Davies G, Bubner T, Holton C, Beilby J, Harris M. How people with chronic illnesses view their care in general practice: a qualitative study. Med J Aust. 2004;181(2):70-3.

18. Wiles R. Empowering practice nurses in the follow-up of patients with established heart disease: lessons from patients' experiences. J Adv Nurs. 1997;26(4):729-35.

19. Bettany-Saltikov J. How to do a systematic literature review in nursing: a step-by-step guide. London: McGraw-Hill Education; 2012

20. Critical Appraisal Skills Programme (CASP). Checklist for qualitative studies. http://media.wix.com/ugd/dded87_29c5b002d99342f788c6ac670e49f274. pdf. Accessed 25 July 2016

21. Charmaz K. Constructing grounded theory. 2nd ed. London: Sage Publications; 2014

22. Blackburn M, Stathi A, Keogh E, Eccleston C. Raising the topic of weight in general practice: perspectives of GPs and primary care nurses. BMJ Open. 2015;5(8):e008546.

23. Oandasan I, Hammond M, Conn L, Callahan S, Gallinaro A, Moaveni A. Family practice registered nurses: the time has come. Can Fam Physician. 2010;56(10):e375-82

24. McKenna L, Halcomb E, Lane R, Zwar N. An investigation of barriers and enablers to advanced nursing roles in Australian general practice. Collegian (Royal College of Nursing, Australia). 2015;22:183-9.

25. Mills J, Chamberlain-Salaun J, Christie L, Kingston M, Gorman E, Harvey C. Australian nurses in general practice, enabling the provision of cervical screening and well women's health care services: a qualitative study. BMC Nurs. 2012;11(1):23-30.

26. Johnson M, Goyder E. Changing roles, changing responsibilities and changing relationships: an exploration of the impact of a new model for delivering integrated diabetes care in general practice. Qual Prim Care. 2005;13(2):85-90.

27. Walsh A, Moore A, Barber A, Opsteen J. Educational role of nurse practitioners in a family practice centre: perspectives of learners and nurses. Can Fam Physician. 2014;60(6):e316-21.

28. Price A, Williams A. Primary care nurse practitioners and the interface with secondary care: a qualitative study of referral practice. J Interprof Care. 2003;17(3):239-50

29. Mitchell J, Brown J, Smith C. Interprofessional education: a nurse practitioner impacts family medicine residents' smoking cessation counselling experiences. J Interprof Care. 2009;23(4):401-9.

30. Main R, Dunn N, Kendall K. Crossing professional boundaries: barriers to the integration of nurse practitioners in primary care. Educ Prim Care. 2007;18(4):480-7.

31. Sunaert $P$, Willems $S$, Feyen $L$, Bastiaens $H$, De Maeseneer J, Jenkins $L$, Nobels F, Samyn E, Vandekerckhove M, Wens J, et al. Engaging GPs in insulin therapy initiation: a qualitative study evaluating a support program in the Belgian context. BMC Fam Pract. 2014;15:1-9.

32. Ehrlich C, Kendall E, St John W. How does care coordination provided by registered nurses "fit" within the organisational processes and professional relationships in the general practice context? Collegian (Royal College of Nursing, Australia). 2013;20(3):127-35.

33. Eley E, Patterson E, Young J, Fahey P, Del Mar C, Hegney D, Synnott R, Mahomed R, Baker P, Scuffham P. Outcomes and opportunities: a nurse-led model of chronic disease management in Australian general practice. Aust J Prim Health. 2013;19:150-8.

34. Ehrlich C, Kendall E, Muenchberger H. Spanning boundaries and creating strong patient relationships to coordinate care are strategies used by experienced chronic condition care coordinators. Contemp Nurse. 2012:42(1):67-75

35. Manski-Nankervis J, Furler J, Blackberry I, Young D, O'Neal D, Patterson E. Roles and relationships between health professionals involved in insulin initiation for people with type 2 diabetes in the general practice setting a qualitative study drawing on relational coordination theory. BMC Fam Pract. 2014;15:1-10.
36. Furler J, Spitzer O, Young D, Best J. Insulin in general practice - barriers and enablers for timely initiation. Aust Fam Physician. 2011;40(8):617-21.

37. Phillips C, Dwan K, Pearce C, Hall S, Porritt J, Yates R, Sibbald B. Time to talk, time to see: changing microeconomies of professional practice among nurses and doctors in Australian general practice. Contemp Nurse. 2007;26(1):136-44.

38. Willis E. Medical dominance. St Leonards: Allen \& Unwin; 1989. Revised edn.

\section{Submit your next manuscript to BioMed Central and we will help you at every step:}

- We accept pre-submission inquiries

- Our selector tool helps you to find the most relevant journal

- We provide round the clock customer support

- Convenient online submission

- Thorough peer review

- Inclusion in PubMed and all major indexing services

- Maximum visibility for your research

Submit your manuscript at www.biomedcentral.com/submit

) Biomed Central 